\title{
Caspian Sea Level changes based on Satellite altimetry
}

\author{
Omid Memarian Sorkhabi \\ (omidmemaryan@gmail.com) \\ Department of Geomatics Engineering, Faculty of Civil Engineering and Transportation, University of Isfahan, \\ Isfahan, Iran.
}

\begin{abstract}
Today, despite the satellite altimetry, it is possible to determine the average sea level and determine the sea level change with high accuracy. In this research, data from 1992-2017 TOPEX / Poseidon, Jason1, OSTM and Jason3 altimeter satellites in the Caspian Sea have been used. The results show that every year the average of $75 \mathrm{~mm}$ of the Caspian Sea water level decreases and the downward trend.
\end{abstract}

Keywords: The Caspian Sea, Sea level, Altimetry, Caspian Sea Level

\section{Introduction}

The history of satellite altimetry to determine the average sea level and geoid dates back to three decades ago [1]. Changes in the Caspian Sea, since it is not connected to open waters, have always been different from global changes in open waters, as it has witnessed major changes in its history [2]. For example, we can mention the sharp rise in water levels in the 1970s and its sharp decline in recent years, which continues. Rising water in the 1970s and the flooding of coastal areas and facilities created a crisis that was examined from different perspectives. Similarly, water shortages in recent years have caused another crisis in the region. As maritime trade in the region is severely threatened. Another case is the separation of Gorgan Bay from the Caspian Sea, which is very imminent as the process of water depletion continues. In the event of this event, an environmental crisis is predicted for the region that could severely affect the Gorgan region. Deep learning can also be help determine sea level [3-11].

In this research, data from 1992-2017 TOPEX / Poseidon, Jason1, OSTM and Jason3 altimeter satellites in the Caspian Sea have been used. 


\section{Results}

The output of the OSTM satellite from 2009 to 2017 is shown in Figure 1.

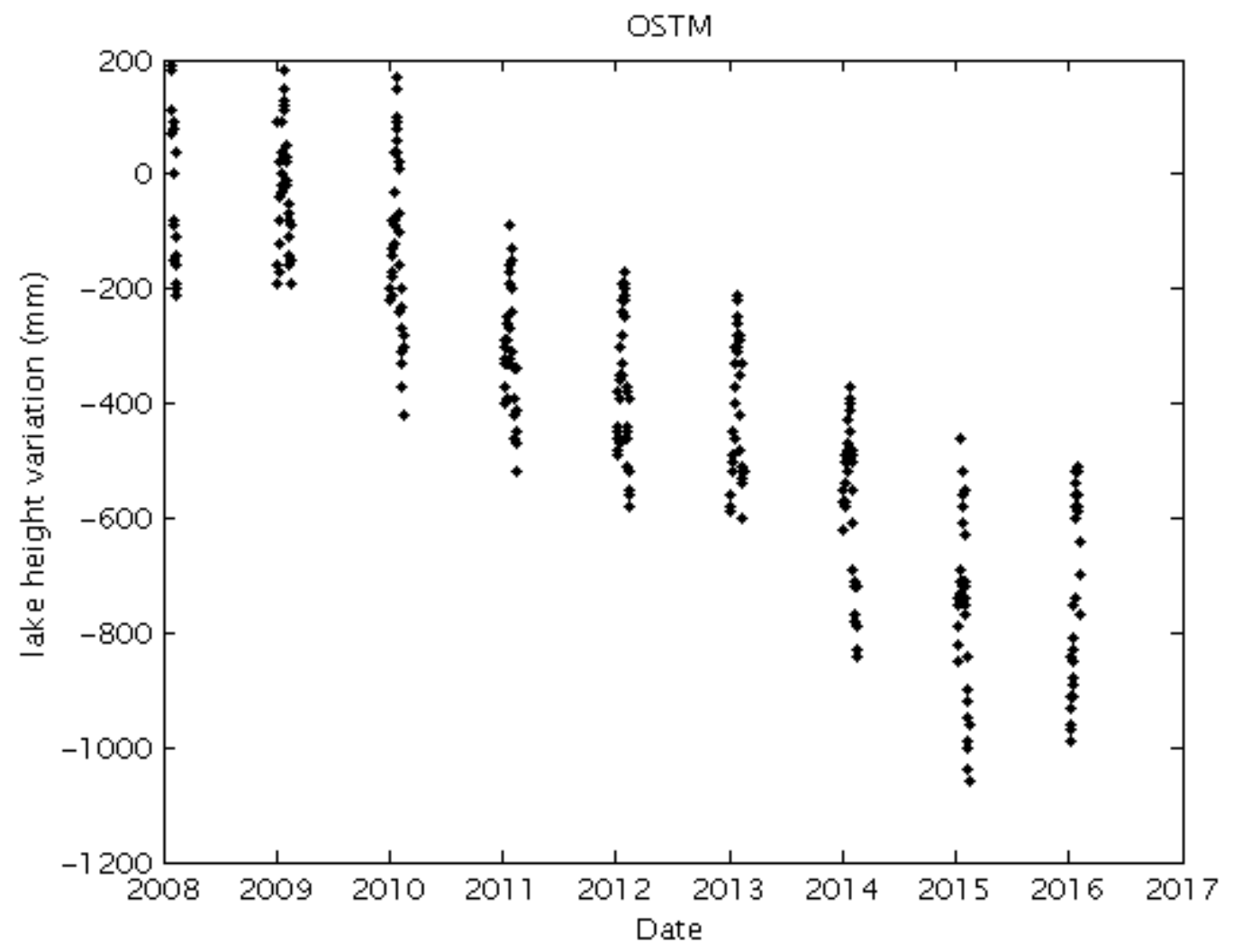

Figure 1 OSTM satellite output from 2009 to 2017

All altimeter satellite outputs are shown in Figure 2. 


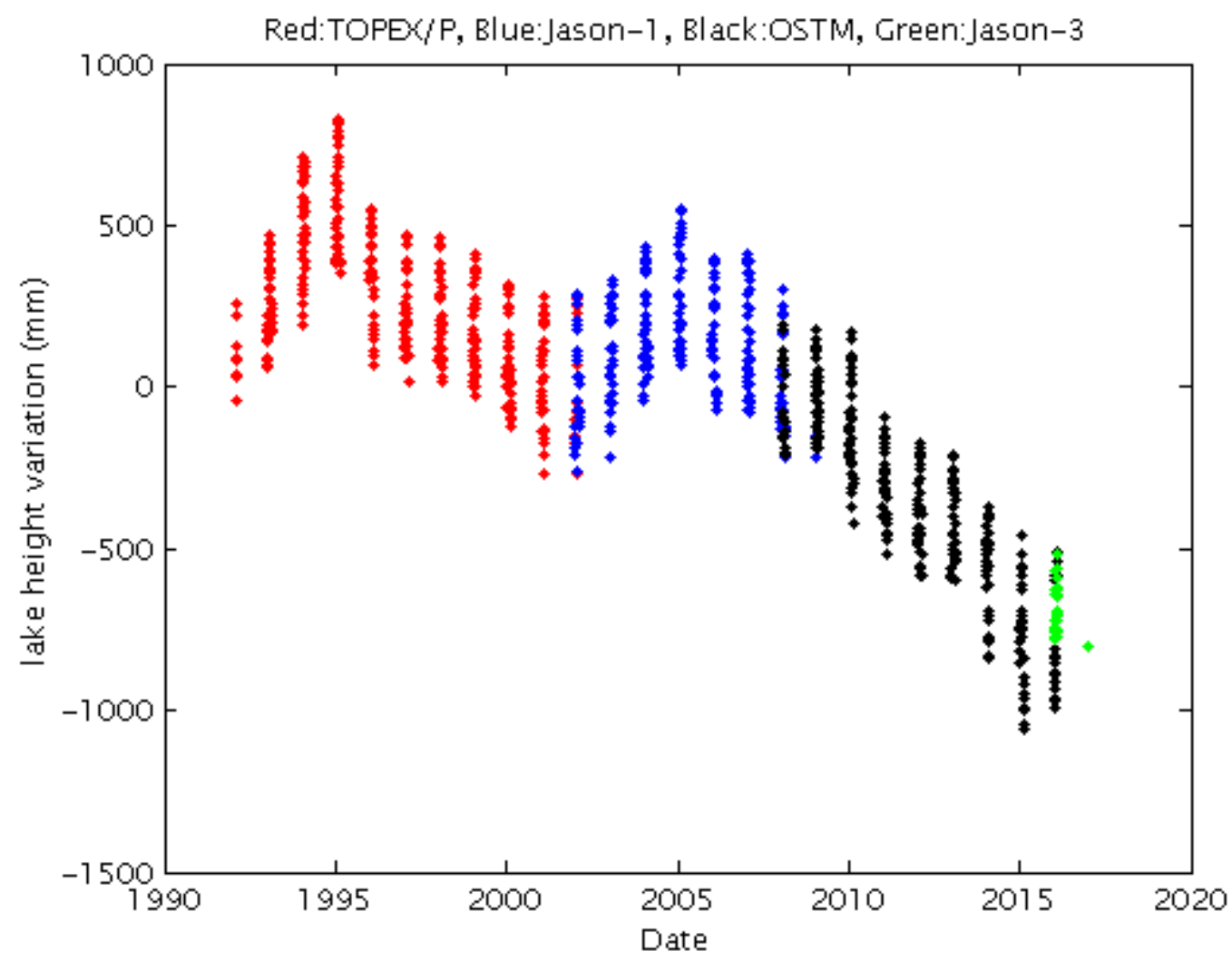

Figure 2: All output of altimeter satellites

Every year, the average $75 \mathrm{~mm}$ of the Caspian Sea water level decreases and the downward trend.

\section{Conclusion}

In this research, data from 1992-2017 TOPEX / Poseidon, Jason1, OSTM and Jason3 altimeter satellites in the Caspian Sea have been used. The results show that every year the average of $75 \mathrm{~mm}$ of the Caspian Sea water level decreases and the downward trend. 


\section{Competing interests:}

The authors declare no competing interests.

\section{References}

[1] Moghaddam EI, Allahdadi MN, Ashrafi A, Chaichitehrani N. Coastal system evolution along the southeastern Caspian Sea coast using satellite image analysis: response to the sea level fall during 1994-2015. Arabian Journal of Geosciences. 2021 May;14(9):1-6.

[2] Gharibreza M, Nasrollahi A, Afshar A, Amini A, Eisaei H. Evolutionary trend of the Gorgan Bay (southeastern Caspian Sea) during and post the last Caspian Sea level rise. Catena. 2018 Jul 1;166:339-48.

[3] Memarian Sorkhabi O, Asgari J, Amiri-Simkooei A. Wavelet decomposition and deep learning of altimetry waveform retracking for Lake Urmia water level survey. Marine Georesources \& Geotechnology. 2021 Mar 10:1-1

[4] Memarian Sorkhabi O. Geoid determination based on log sigmoid function of artificial neural networks:(a case study: Iran). Journal of Artificial Intelligence in Electrical Engineering. 2015 Mar 1;3(12):18-24.

[5] Sorkhabia OM, DJAMOUR Y. Wavelet Transform Analysis of Ionospheric Electron Content Changes before Large Earthquakes. Journal of Geomatics Science and Technology, 2015.

[6] Sorkhabi OM, Naderi A, Emadi R. Terrain Effect on Geoid Determination Case Study: NW Iran. Journal of Geomatics Science and Technology. 2014 Nov 10;4(2):139-48.

[7] Sorkhabi OM. Deep learning of dynamic sea-level variability to investigate the relationship with the floods in Gothenburg. 2021. DOI: 10.21203/rs.3.rs-422515/v1

[8] Memarian Sorkhabi O, Asgari J, Amiri-Simkooei A. Monitoring of Caspian Sea-level changes using deep learning-based 3D reconstruction of GRACE signal. Measurement. 2021 Apr 1;174:109004.

[9] Sorkhabia OM, Asgaria J, Amiri-Simkooeia A. Caspian Sea Level Survey with GRACE and GRACE-FO. 2020.

[10] Memarian Sorkhabi O, Djamour Y. Estimation of Geodetic Virtual Velocity Based On Back Propagation Artificial Neural Networks (Case Study: NW Iran). Journal of Geoscience. 2015 Jun 1;24(95):69-76.

[11] Memarian Sorkhabi O, Asgari J, Amiri Simkooei A. Analysis of Greenland mass changes based on GRACE four-dimensional wavelet decomposition. Remote Sensing Letters. 2021 May 4;12(5):499-509. 